\title{
Evaluation of methods used to estimate inhaled dose of carbon monoxide
}

\author{
P J REES, CLAIR CHILVERS, AND T J H CLARK \\ From the Clinical Science Laboratories, Guy's Hospital Medical School, London
}

ABSTRACT We have compared estimation of alveolar carbon monoxide measured either as endexpired or mixed-expired carbon monoxide tension with two spectrophotometric estimations of venous blood carboxyhaemoglobin $(\mathrm{COHb})$. Estimation of mixed-expired carbon monoxide proved more convenient for patients than the end-expired method, and this estimation of carbon monoxide exposure discriminated between non-smokers and smokers as well as measurements of $\mathrm{COHb}$. The technique is bloodless, economical, and simple to perform. It should prove a valuable method for validating reported smoking habits of people attending smoking advisory centres and for epidemiological surveys of smoking.

The reliability of reported cigarette consumption of subjects attending for follow-up in smoking advisory centres is notoriously poor. Sillett et $a l^{1}$ found that 44 out of 133 such subjects who claimed to have stopped smoking had levels of venous blood carboxyhaemoglobin ( $\mathrm{COHb}$ ) which made their claims doubtful. In order to assess the success rates in such clinics and for other epidemiological work it is desirable to have a simple means of confirming smoking habits.

Carboxyhaemoglobin levels are generally higher in smokers than non-smokers although the ranges overlap. The COHb levels reflects exposure to carbon monoxide in cigarette smoke which is determined by the number and type of cigarette as well as the manner of smoking. It is also raised by exposure to carbon monoxide in ambient air, and its range of removal from the blood is slow and depends in part on the degree of physical activity.

Most reported measurements of $\mathrm{COHb}$ have used a venous blood sample and recently have been performed spectrophotometrically on an IL 182 CO-Oximeter. Many workers have found the IL 182 CO-Oximeter unstable ${ }^{2}$ but the technique is simple and applicable to the analysis of large numbers of samples. The earlier spectrophotometric method of $\mathrm{COHb}$ estimation described by Commins and Lawther ${ }^{3}$ requires only a finger prick sample and is more reliable but it is tech-

Address for reprint requests: Professor TJH Clark, Respiratory Function Unit, Guy's Hospital, London SE1 9RT. nically more difficult to perform. Other methods available use gas chromatography ${ }^{4}$ and infrared spectrophotometry. ${ }^{5}$

Jones $e t a l^{6}$ showed that the level of carbon monoxide in the end-expired gas after a breathhold of 20 seconds at total lung capacity correlated well with the venous $\mathrm{COHb}$ level. This method requires an apparatus to collect the end-expired gas after discarding its first part. The level of end-expired carbon monoxide is thought to approximate to alveolar carbon monoxide (PACO). Rawbone et al ${ }^{7}$ have described an alternative estimation of PACO in which carbon monoxide in mixed-expired gas is measured and an allowance made for estimated dead space. In our experience subjects have found this latter mixed-expired measurement of PACo easier to perform than the earlier end-expired measurement.

We have compared the mixed-expired and endexpired estimations of PACO and have evaluated the mixed-expired method against $\mathrm{COHb}$ estimated by the IL 182 CO-Oximeter and by the spectrophotometric method of Tietz and Fiereck ${ }^{8}$ which was the reference method used by Rawbone et al in their original description of the mixed-expired estimation.

\section{Methods}

IL 182 CO-OXIMETER

The IL 182 CO-Oximeter was calibrated at the beginning of the study with blood at $0 \%$ and $100 \%$ 
COHb. Lithium heparin was used as an anticoagulant and all samples were analysed within one hour of being taken. After the initial calibration a regular check was made that the same nonsmokers' blood at the same time of day produced a consistent value.

\section{SPECTROPHOTOMETRY}

Samples were analysed on a Beckman spectrophotometer by the method of Tietz and Fiereck. ${ }^{8}$ Blood was haemolysed by dilution with $0.4 \%$ ammonium hydroxide and oxyhaemoglobin was reduced with sodium dithionate. The absorbance of the sample was read at $541 \mathrm{~nm}$ and $555 \mathrm{~nm}$ and the ratio of these two absorbances compared with that for $0 \%$ and $100 \% \mathrm{COHb}$. Tietz and Fiereck showed that the relationship between the absorbance ratio and the $\mathrm{COHb}$ percentage was linear over the entire range and this was used to calculate $\mathrm{COHb}$ from the absorbance ratio.

\section{MIXED-EXPIRED ESTIMATION OF ALVEOLAR} CARBON MONOXIDE

Alveolar carbon monoxide was estimated by the mixed-expired method using an infrared carbon monoxide analyser (Analytical Development Company Ltd). The subject breathed tidally through a one-way valve with a dry gas meter on the inspiratory side. The expired gas was sampled after passing through a container of soda lime and calcium chloride to absorb carbon dioxide and water vapour. This container also served as a mixing chamber for the expired gas. The subject breathed through the apparatus until a steady level was recorded on the carbon monoxide analyser (usually between 10 and 20 breaths). Mean tidal volume was calculated from the volume of inspired air measured on the dry gas meter and the number of breaths. The concentration of carbon monoxide in alveolar air was calculated from the equation:

$$
\text { FAco }=\frac{V_{T} \times \text { Feco }-V_{D} \times \text { Fico }}{V_{T}-V_{D}}
$$

where FACO is the fractional concentration of carbon monoxide in alveolar air, Fico the concentration in inspired air, Feco the mixed-expired concentration, $V_{T}$ the mean tidal volume, and $V_{D}$ the dead space estimated as $1 \mathrm{ml}$ per $\mathrm{lb}$ of ideal bndy weight. Alveolar carbon monoxide was calculated from the fractional concentration and barometric pressure assuming an alveolar partial pressure of carbon dioxide of $5.32 \mathrm{kPa}(40 \mathrm{mmHg})$. The calibration of the $\mathrm{CO}$ meter was checked several times a day with gas mixtures containing 0 ppm CO and 98 ppm CO (PK Morgan Ltd).

\section{END-EXPIRED ESTIMATION OF ALVEOLAR}

The mixed-expired estimation of PACO was com- $\frac{\bar{c}}{\bar{c}}$ pared with the end-expired estimation of Jones $e t \overrightarrow{\widetilde{\sigma}}$ al. ${ }^{6}$ After a 30 second breathhold at total lung 0 capacity the subject performed a maximal ex-co piration. Approximately the first $500 \mathrm{ml}$ of the $\vec{\circ}$ expired gas was discarded and the carbon monoxide level was measured in the remainder $\vec{\omega}$ of the expirate.

The first three methods were compared in four $\stackrel{\vec{x}}{x}$ non-smokers and 25 smokers using three esti-c mations by each method. These results were usedto assess the variation of each method of estimation. The results of 70 estimates of mixed-o expired PACo and $\mathrm{COHb}$ by $\mathrm{CO}-$ Oximeter wereused to produce prediction of $\mathrm{COHb}$ from PACO.

In a further 28 subjects, composed of 14 smokers? and 14 non-smokers, single mixed-expired and end-expired estimations of PACO were compared to study their correlation. Finally 160 subjects were $e_{\infty}^{\circ}$ recruited from hospital staff and a smokers' clinic ${ }^{\circ}$ for a comparison to be made between mixed-D expired PACO and their reported smoking habits.

\section{Results}

COMPARISON OF CO-OXIMETER AND SPECTROPHOTOMETRIC ASSESSMENTS OF COHb WITH MIXED-EXPIRED PACO

Three measurements by each method were made. on four non-smokers and $\mathbf{2 5}$ smokers, so that in alf nine measurements were made on each subject:은 Analysis of variance was carried out using the datax from each measurement method in turn. This separated out variability between subjects (which as expected, was considerable) from intra-subjece variability. The CO-Oximeter and mixed-expired PACO each had a coefficient of variation of $6 \%$ compared with $22 \%$ for the spectrophotometrie method. With the latter method only $80 \%$ of tota年. variability was attributable to variability between subjects compared with $97 \%$ and $98 \%$ for PACQ0 and CO-Oximeter respectively. Therefore, the repeatability of the spectrophotometric method of Tietz and Fiereck ${ }^{8}$ is less than the other methods? When the COHb level of the blood was raised to $40-60 \%$ the standard deviation of the sepctro photometric method was slightly less $(1.7 \%$ COHb cf $1.9 \% \mathrm{COHb}$ ) with a coefficient of variation of $3 \%$ which is close to the value of $2.4 \%$ found $b \frac{8}{5}$ Tietz and Fiereck at a COHb level of $40 \%$. The repeatability of the CO-Oximeter is comparable to that reported by Mass et al. ${ }^{5}$ 
PREDICTION OF COHb FROM MIXED-EXPIRED PaCo

In order to transform the results of the estimation to $\mathrm{COHb} \%$ a prediction equation was calculated using regression methods for 70 comparative values from the mixed-expired method and the COOximeter. These results produced the following prediction equation:

$$
Y=3.95 x-0.32 x^{2}-2 \cdot 4
$$

where $x$ is PAco in pascals $(\mathrm{Pa})$ and $\mathrm{Y}$ is $\% \mathrm{COHb}$. The results are shown graphically in fig 1 .

\section{COMPARISON OF MIXED-EXPIRED WITH}

END-EXPIRED PACO

Subjects who were not accustomed to performing physiological measurements sometimes found the end-expired Paco estimation after 30 seconds breathhold difficult to perform. The two methods of obtaining PACO were compared in 28 subjects and were in good agreement (fig 2). The maximum discrepancy was $0.36 \mathrm{~Pa}(0.003 \mathrm{mmHg})$ and there was no significant difference between the two estimates using a $t$ test.

\section{MIXED-EXPIRED PACO IN SMOKERS AND}

\section{NON-SMOKERS}

Alveolar carbon monoxide was estimated by mixed-expired method in 161 subjects. Forty-nine

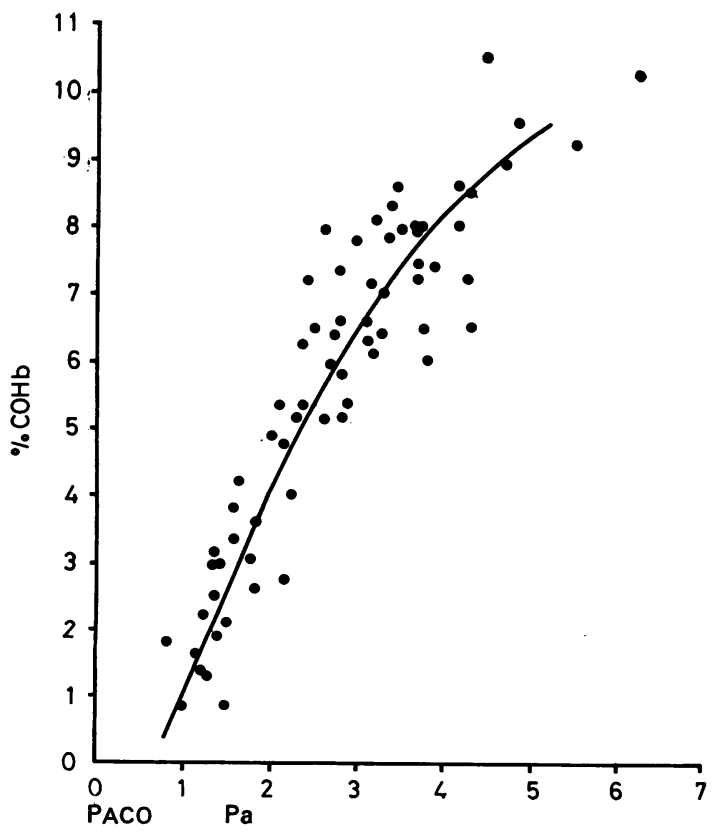

Fig 1 Venous carboxyhaemoglobin $(\% \mathrm{COHb})$ estimated by IL 182 CO-Oximeter related to PACo estimated by the mixed-expired method.

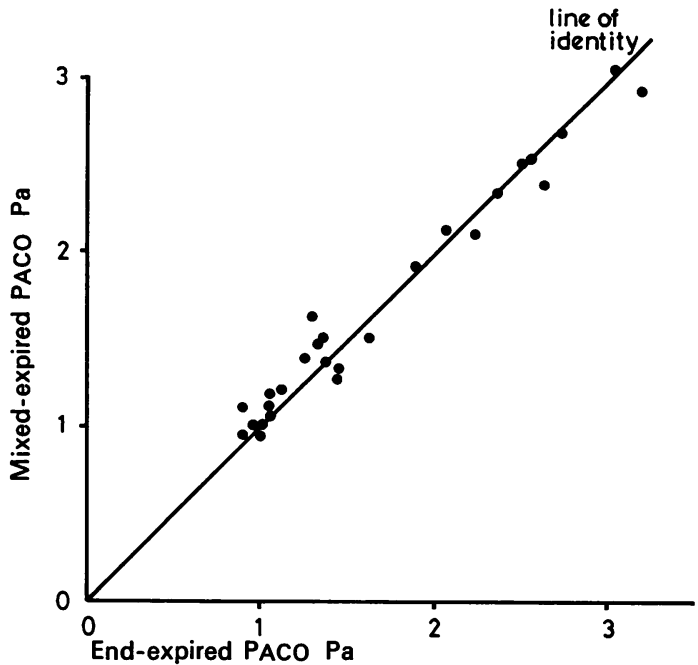

Fig 2 Paco estimated by mixed-expired and end-expired methods. Solid line shows the line of identity between the two estimations.

of these were non-smokers whose claim of nonsmoking was thought to be reliable. The other 112 smokers were carefully questioned about their current smoking habit and although no account was taken of the time since their last cigarette all had smoked in the previous $\mathbf{2 4}$ hours. The values of PACo found in the different groups are shown in fig 3. Our upper limit for non-smokers based on mean $+2 \mathrm{SD}$ is $1.57 \mathrm{~Pa}$ which is equivalent to $3.0 \% \mathrm{COHb}$ using our prediction equation. The highest level observed in a non-smoker was 1.64 pa.

Five out of 14 smokers of 10 or less cigarettes per day had a Paco level of less than $1.57 \mathrm{~Pa}$ compared to two out of 59 smokers of 11-20 cigarettes per day, and none of the 39 smokers of more than 20 cigarettes per day. It seems unlikely that PACo of greater than $1.6 \mathrm{~Pa}$ will be found in a non-smoker unless they have recently been exposed to high ambient levels of carbon monoxide.

\section{Discussion}

The comparison of two estimations of venous carboxyhaemoglobin with the mixed-expired estimation of alveolar carbon monoxide indicates that the spectrophotometric method of Tietz and Fiereck ${ }^{8}$ is too variable for reliable estimation of $\mathrm{COHb}$ levels in the $0-12 \%$ range found in smokers. When the COHb level was raised to $40 \%$ the coefficient of variation approximated to that found by Tietz and Fiereck, indicating that our technique was comparable to that originally described. 


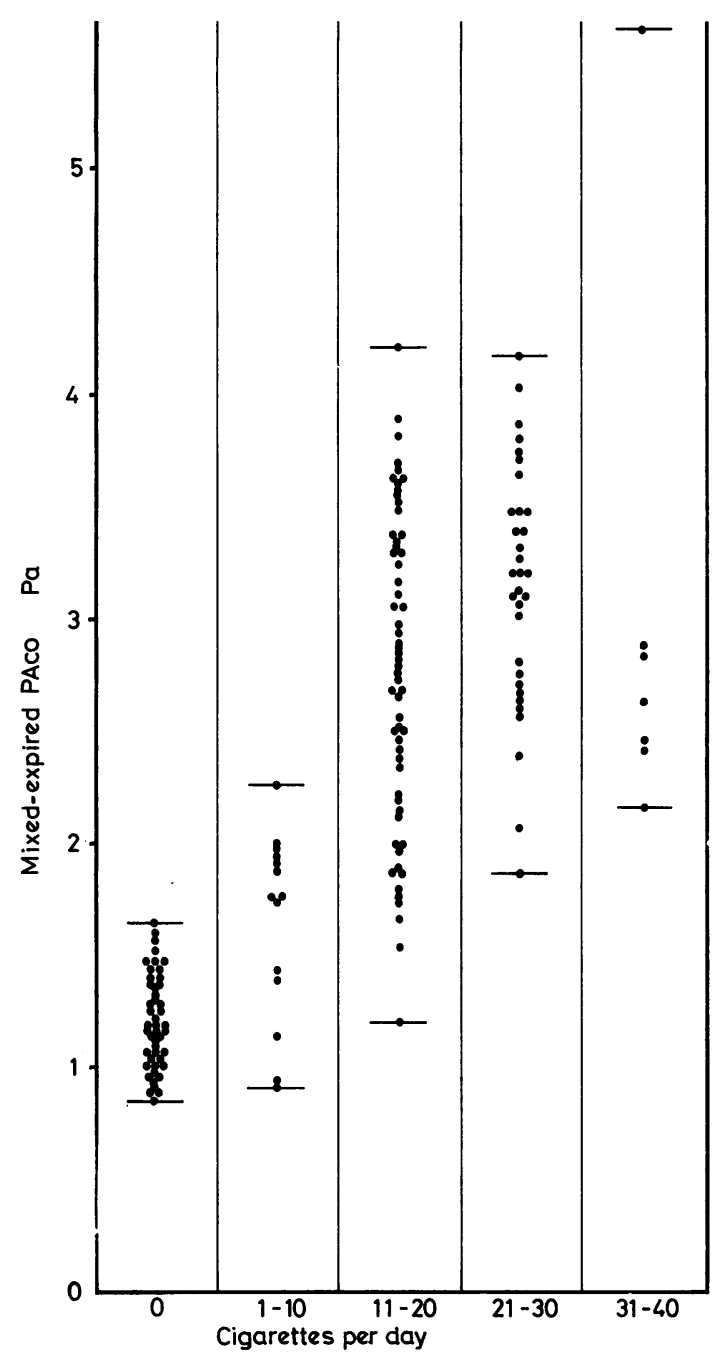

Fig 3 PACO in non-smokers and smokers of different numbers of cigarettes. Horizontal bars indicate limits of the ranges.

Despite its problems the IL 182 CO-Oximeter produces results which were more reproducible and the measurement was much simpler to perform. The IL 282 which has now replaced the IL 182 is claimed to be a more stable instrument but it is considerably more expensive at a cost of $£ 7830$.

The infrared carbon monoxide analyser used for the estimations of PACO costs less (£2250), and its other attraction is that it does not require a blood sample-the mixed-expired estimation merely requires subjects to breathe normally into a mouthpiece for about one minute. We have found that the Paco obtained by the mixed-expired methods is in good agreement with that estimated by the end-expired method which has been more widel used. ${ }^{6}{ }^{9}$ Our results for the relation between Paco and $\mathrm{COHb}$ are similar to those found previousl $\$$ and confirm a curved correlation which probably reflects the interference of oxygen with the PACO? $\mathrm{COHb}$ relationship when levels of around $10 \%$ $\mathrm{COHb}$ are reached.

We have used the mixed-expired PACo tech nique at smokers' clinics in the Guy's Healt District and have been impressed by its usefulness In order to assess the response to treatment if such a clinic it is essential to have an objective assessment to confirm statements of current smoking habit which are often unreliable. We believe that the mixed-expired estimation of PACO is the simplest, reliable method available.

An additional benefit is that a subject wh $\overrightarrow{8}$ decreases smoking is able to see a decreasing PAco level which provides an added incentive compared with simple respiratory function testeo which generally fail to show any change in the short run. Judging by our results a claim to none smoking in a subject with a PACo level of above $1.6 \mathrm{~Pa}$ should be treated with caution. The overla $\bar{B}$ between smokers and non-smokers is similar to that seen using venous carboxyhaemoglobi? levels. ${ }^{10}$ The range of $\mathrm{COHb}$ levels found in none smokers varies in different studies. Both Wald $e \vec{t}$ $a l^{11}$ and Sillett $e t a l^{1}$ found lower ranges for non smokers but our upper limit is close to that found. by $\mathrm{Cole}^{12}$ in a hospital outpatient department an a London office, and the range is similar to thaf found by other workers in Finland, ${ }^{13}$ England, and America. ${ }^{10}$ The differences reflect technique and subject differences and indicate that each laboratory should establish its own range for non smokers, and its own prediction equation if equivalent levels of $\mathrm{COHb}$ are required.

Although the $\mathrm{CO}$ meter requires at least at hour to warm up it is relatively portable. Its vari ability is similar to the most commonly use method of estimating venous $\mathrm{COHB}$, and its ease of use without the necessity of venepunctures makes it suitable for general epidemiological use as well as monitoring results of advice about smoking.

We thank Imperial Tobacco Ltd for support.

\section{References}

1 Sillett RW, Wilson MB, Malcolm RE, Ball KPO Deception among smokers. $\mathrm{Br}$ Med J 1978: $2 \mathrm{P}$ 1185-6. 
2 Cole PV. Estimation of blood-carboxyhaemoglobin. Lancet 1974; 2:1010-11.

3 Commins BT, Lawther PJ. A sensitive method for the determination of carboxyhaemoglobin in a finger prick sample of blood. $\mathrm{Br} J$ Ind Med 1965; 22:139-43.

4 Collison HA, Rodkey FL, O'Neal JD. Determination of carbon monoxide in blood by gas chromatography. Clin Chem 1968; 14:162-71.

5 Mass AHJ, Hamelink ML, De Leeuw RJM. An evaluation of the spectrophotometric determination of $\mathrm{HbO}_{2}$ and $\mathrm{Hb}$ in blood with the $\mathrm{CO}$ Oximeter IL 182. Clin Chim Acta 1970; 29:303-9.

6 Jones RH, Ellicott MF, Cadigan JB, Gaensler EA. The relationship between alveolar and blood carbon monoxide concentrations during breathholding. J Lab Clin Med 1958; 51:553-64.

7 Rawbone RG, Coppin CA, Guz A. Carbon monoxide in alveolar air as an index of exposure to cigarette smoke. Clin Sci Mol Med 1976; 51:495501.

8 Tietz NW, Fiereck EA. The spectrophotometric measurement of carboxyhemoglobin. Ann Clin Lab Sci 1973; 3:36-42.

9 Stewart RD, Stewart RS, Stamm W, Seelen RP. Rapid estimation of carboxyhemoglobin level in fire fighters. JAMA 1976; 235:390-2.

10 Stewart RD, Baretta ED, Platte LR et al. Carboxyhemoglobin levels in American blood donors. JAMA 1974; 229:1187-95.

11 Wald N, Idle M, Bailey A. Carboxyhaemoglobin levels and inhaling habits in cigarette smokers. Thorax 1978; 33:201-6.

12 Cole PV. Comparative effects of atmospheric pollution and cigarette smoking on carboxyhaemoglobin levels in man. Nature 1975; 255:699-701.

13 Seppänen A. Smoking in closed space and its effect on carboxyhaemoglobin saturation of smoking and nonsmoking subjects. Ann Clin Res 1977; 9:281-3.

14 Russell MAH, Cole PV, Brown E. Absorption by non-smokers of carbon monoxide from room air polluted by tobacco smoke. Lancet 1973; 1:576-9. 